\title{
Not All Patients With Non-erosive Reflux Disease Share Psychological Distress as Main Mechanism of Disease: Author's Reply
}

TO THE EDITOR: I appreciate the interest and comments ${ }^{1}$ on our paper, which was published in October 2013 issue of this journal. $^{2}$ As you have commented, non-erosive reflux disease (NERD) is known as heterogeneous group from pathophysiological aspect. In our paper, NERD is defined as patients with typical symptoms of gastroesophageal reflux disease (GERD) such as heartburn or acid regurgitation without endoscopic erosion. ${ }^{2}$ This study was health check-based study. Therefore, we did not measure esophageal $\mathrm{pH}$ nor exclude esophageal hypersensitivity or functional heartburn. In our article, NERD was associated with psychological distress, such as somatization and anxiety, and irritable bowel syndrome (IBS) was also associated with somatization, anxiety and hostility. Psychological distress will be one of many pathophysiological mechanisms of IBS and NERD. NERD in our study was also associated with female sex and high waist circumference. The risk factors of NERD were far different from erosive esophagitis except waist circumference. Many studies have suggested that NERD and erosive esophagitis are both comprised in GERD but their pathophysiologic mechanisms are not the same. They share some mechanisms or risk factors but do not share exactly the same mechanisms or risk factors.

Atypical GERD symptoms (globus sensation, hoarseness, epigastric soreness and chronic cough) were measured with previously validated questionnaires ${ }^{3}$ and they were also associated with psychological distress. As you commented, the causal relationship between reflux and extra-esophageal symptoms is con- troversial issue and this is not the main focus in our article. Therefore, we have just analyzed the association between atypical GERD symptoms and psychological distress without further analysis.

IBS was strongly related with NERD but not with erosive esophagitis in our study. Our conclusion is that IBS shared many risk factors with NERD but not with erosive esophagitis and it partially explains why IBS was associated with NERD but not with erosive esophagitis. If readers carefully read the abstract and manuscripts, they can interpret this result correctly.

Su Youn Nam

Department of Internal Medicine Center for Cancer Prevention \& Detection, National Cancer Center, Goyang, Gyeonggi-do, Korea

1. Savarino E, Zentilin P, Furnari M, Bodini G, Marabotto E, Savarino V. Not all patients with non-erosive reflux disease share psychological distress as main mechanism of disease. J Neurogastroenterol Motil 2014;20:129-130.

2. Nam SY, Ryu KH, Park BJ. Irritable bowel syndrome is associated with gastroesophageal reflux symptom but not erosive esophagitis. J Neurogastroenterol Motil 2013;19:521-531.

3. Kim N, Lee SW, Cho SI, et al. The prevalence of and risk factors for erosive oesophagitis and non-erosive reflux disease: a nationwidemulticenter prospective study in Korea. Aliment Pharmacol Ther 2008;27:173-185.

\section{Conflicts of interest: None.}

